\title{
Increase in prophylaxis of glucocorticoid-induced osteoporosis by pharmacist feedback: a randomised controlled trial
}

\author{
C. Klop • F. de Vries • T. Vinks • M. J. Kooij • T. P. van Staa • \\ J. W. J. Bijlsma • A. C. G. Egberts • M. L. Bouvy
}

Received: 27 June 2013 / Accepted: 16 October 2013 / Published online: 13 November 2013

(C) The Author(s) 2013. This article is published with open access at Springerlink.com

\begin{abstract}
Summary The aim of this study was to determine whether feedback by pharmacists to prescribers of patients eligible for glucocorticoid-induced osteoporosis prophylaxis would stimulate the prescribing of osteoporosis prophylaxis. The
\end{abstract}

C. Klop · F. de Vries $\cdot$ M. J. Kooij • T. P. van Staa

A. C. G. Egberts $\cdot$ M. L. Bouvy

Utrecht Institute for Pharmaceutical Sciences, Division of

Pharmacoepidemiology \& Clinical Pharmacology, Utrecht

University, Universiteitsweg 99, 3584 CG Utrecht, The Netherlands

F. de Vries · T. P. van Staa

MRC Lifecourse Epidemiology Unit, Southampton General

Hospital, Southampton, UK

F. de Vries

Department of Clinical Pharmacy \& Toxicology, Maastricht

University Medical Centre, Maastricht, The Netherlands

F. de Vries

Maastricht University/CAPHRI, Maastricht, The Netherlands

T. Vinks

Pharmacy DeLeij, Tilburg, The Netherlands

J. W. J. Bijlsma

Department of Rheumatology \& Clinical Immunology, University

Medical Centre, Utrecht, The Netherlands

\section{A. C. G. Egberts}

Hospital Pharmacy, University Medical Centre, Utrecht, The Netherlands

M. L. Bouvy $(\bowtie)$

SIR Institute for Pharmacy Practice and Policy, Leiden, The Netherlands

e-mail: m.1.bouvy@uu.nl intervention did not significantly increase the prescribing of bisphosphonates in the total study population, but a significant increase was seen in men and in the elderly. However, the proportion of bisphosphonate-treated patients remained low. Introduction The aim of this study was to determine whether feedback by pharmacists to prescribers of patients eligible for glucocorticoid-induced osteoporosis prophylaxis (GIOP) would stimulate the implementation of the Dutch GIOP guideline.

Methods This randomised controlled trial included 695 patients who were dispensed $\geq 675 \mathrm{mg}$ prednisone equivalents without a concomitant bisphosphonate prescription within 6 months before baseline. Pharmacists were asked to contact the physicians of GIOP-eligible patients in the intervention group to suggest osteoporosis prophylaxis. The primary endpoint was a bisphosphonate prescription. Secondary endpoints were a prescription of calcium supplements, vitamin D or any prophylactic osteoporosis drug (bisphosphonate, calcium supplements, vitamin D).

Results The group assigned to the intervention was slightly younger than the control group (68.7 \pm 15.4 vs. $65.9 \pm$ 16.9 years, $p=0.02$ ) and used hydrocortisone more often ( $7.0 \%$ vs. $3.1 \%, p=0.02$ ). Within 6 months, the intervention did not significantly increase the prescribing of bisphosphonates $(11.4 \%$ after intervention vs. $8.0 \%$ for controls; hazard ratio [HR] 1.47, $95 \%$ confidence interval [CI] 0.91-2.39). However, subgroup analyses showed a significant increase for the primary endpoint in men $(12.8 \%$ vs. $5.1 \%$, HR $2.53,95 \%$ CI $1.11-5.74)$ and patients $\geq 70$ years (13.4 \% vs. $4.9 \%$, HR 2.88, $95 \%$ CI 1.33-6.23). The prescribing of calcium and vitamin $\mathrm{D}$ was not significantly altered.

Conclusion This study showed that active identification of patients eligible for GIOP by pharmacists did not significantly 
increase the prescribing of bisphosphonates in the total study population, but there was an increase in men and the elderly. However, the proportion of GIOP-treated patients remained low.

Keywords Glucocorticoid-induced osteoporosis . Intervention $\cdot$ Pharmacist $\cdot$ Physician

\section{Introduction}

The use of glucocorticoids, even in low doses, is associated with rapid bone loss and an increased risk of fractures [1-4]. Bisphosphonates have been shown to be the most effective drugs for glucocorticoid-induced osteoporosis prophylaxis (GIOP) [5, 6] and are therefore recommended in (inter)national guidelines for management of GIOP [7-9]. The most important recommendation in the Dutch guideline is to consider starting bisphosphonates in post-menopausal women and men over 70 years who are expected to be treated with $>7.5 \mathrm{mg}$ prednisone (equivalents) per day for at least 3 months. In addition, all other patients who are expected to use $>15 \mathrm{mg}$ prednisone (equivalents) for more than 3 months should be treated with bisphosphonates. Although the awareness of the importance of osteoporosis prophylaxis seems to have increased [10], the widespread implementation of guidelines remains difficult. Audits have shown that only $10-60 \%$ of patients who are eligible for GIOP receive appropriate treatment [11-14]. Previous intervention trials that aimed to increase GIOP were mostly conducted by training of physicians (general practitioners and rheumatologists) and frequently included education of patients at risk of GIOP [15-18]. Unfortunately, these attempts have yielded limited success.

Until now, a limited number of studies have determined the impact of pharmacy-based interventions with regard to GIOP $[15,19]$. In the Dutch health care system, pharmacists share a responsibility with prescribers to properly inform patients on the advantages and disadvantages of pharmacotherapy and to assist physicians in this respect. Therefore, pharmacists could play an important role in the implementation of guidelines for management of GIOP. The previously conducted studies that used a pharmacy-based approach for the improvement of GIOP have shown a significant increase in the prescribing rates of prophylactic osteoporosis drugs. However, these studies were limited by a lack of randomisation [15] and a lack of power [19]. Therefore, the aim of this randomised controlled trial was to determine whether feedback by community pharmacists to physicians of patients eligible for GIOP would stimulate the implementation of the Dutch GIOP guideline.

\section{Materials and methods}

Study participants and setting

This randomised controlled trial was conducted at 29 pharmacies from different parts in the Netherlands. Pharmacists were invited to participate in the study by a short announcement in the Dutch Pharmacy Journal. The pharmacies were located all over the Netherlands. There was no particular chain of pharmacies involved.

At each participating pharmacy, drug dispensing data from all patients were collected at baseline (date of first data extraction, January 2005 to May 2005). We selected all patients who were dispensed $\geq 675 \mathrm{mg}$ prednisone equivalents ( $\geq 67.5$ defined daily dosages [DDDs] [7, 8]) without a concomitant bisphosphonate prescription within the 180 days before baseline and with at least one prescription for a glucocorticoid within the 90 days before baseline. In the Netherlands, the vast majority of the population obtains their medication from only one community pharmacy, enabling the collection of longitudinal medication histories [20]. Medication records of patients were pseudonymised and were sent to the researchers. We have excluded patients who had less than 6 months of medication records before baseline.

\section{Intervention}

Block randomisation (using the survey select procedure of SAS, version 8.2) was performed. After the randomisation, the pharmacists received feedback on patients who were assigned to the intervention group. They received a letter with the Dutch GIOP guideline [8] and a list on paper with all the eligible patients. Pharmacists were expected to forward the patients on this list to their own general practitioners and to suggest the start of osteoporosis prophylaxis (a bisphosphonate). It was left at the disposal of the individual pharmacist how to communicate with the general practitioner.

At the end of 6 months of follow-up, additional pharmacy dispensing records of all patients in the intervention and control group (usual care) were retrieved. These medication records were reviewed for the dispensing of bisphosphonates, calcium supplements and vitamin D during the follow-up period. After the study period, pharmacists received comparable information on patients who were originally assigned to the control group.

This study was not covered by the Medical Research Involving Human Subjects Act (WMO) since the patients were not directly exposed to the intervention, and approval by an ethical committee was not required.

\section{Outcome measurements}

All patients were followed up from baseline until the start of osteoporosis prophylaxis or the end of the study period (the 
date of second data extraction), whichever came first. The primary endpoint was a dispensing of a bisphosphonate. Secondary endpoints were the dispensing of other prophylactic osteoporosis drugs (calcium supplements or vitamin D) and a dispensing of any prophylactic osteoporosis drug as a composite endpoint (bisphosphonate, calcium supplements or vitamin D, only the first event was counted).

\section{Statistical analyses}

We assumed an event rate of $10 \%$ in the control group over 6 months and an increase to $20 \%$ in the intervention group $[18,21]$. With a two-sided alpha of 0.05 and $90 \%$ power, a total sample size of 584 patients was estimated which was increased to 695 patients.

Chi-square tests or Fisher's exact tests were used to determine baseline differences between the comparison groups for categorical variables and independent sample $t$ tests for continuous variables $(p<0.05)$. Cox proportional hazard models were used to estimate hazard ratios (HRs) for the start of osteoporosis prophylaxis during the follow-up period by comparing the intervention group to the control group. Hazard ratios were adjusted for covariates that were unevenly distributed between the intervention group and control group $(p<0.05)$. Patients who did not receive any prescription of glucocorticoids during the follow-up period were censored at 1 day after baseline.

In subgroup analyses, results were stratified by gender, the number of prednisone equivalents (DDDs) received in the 6 months before baseline $(67.5-134,135-270,>270)$ and age categories $(\leq 70,>70$ years $)$ for the primary and composite endpoint.

Finally, a Kaplan-Meier plot was used to visualize the time to start of bisphosphonate use after baseline and the proportion of patients being newly treated for GIOP during the study period. This plot was stratified by the randomised intervention.

All analyses were performed using SAS, version 9.1.

\section{Results}

During the first data extraction period, 735 patients were selected from the participating pharmacies. Of these patients, $31(4.2 \%)$ were not eligible for bisphosphonate prophylaxis according to the Dutch guideline. These patients were either females younger than 50 years or males younger than 70 years using less than 1,350 mg (135 DDDs) prednisone equivalents, or females older than 50 or males older than 70 using less than $675 \mathrm{mg}$ (67.5 DDDs) prednisone equivalents. Moreover, nine
Fig. 1 Flow chart of the study procedure

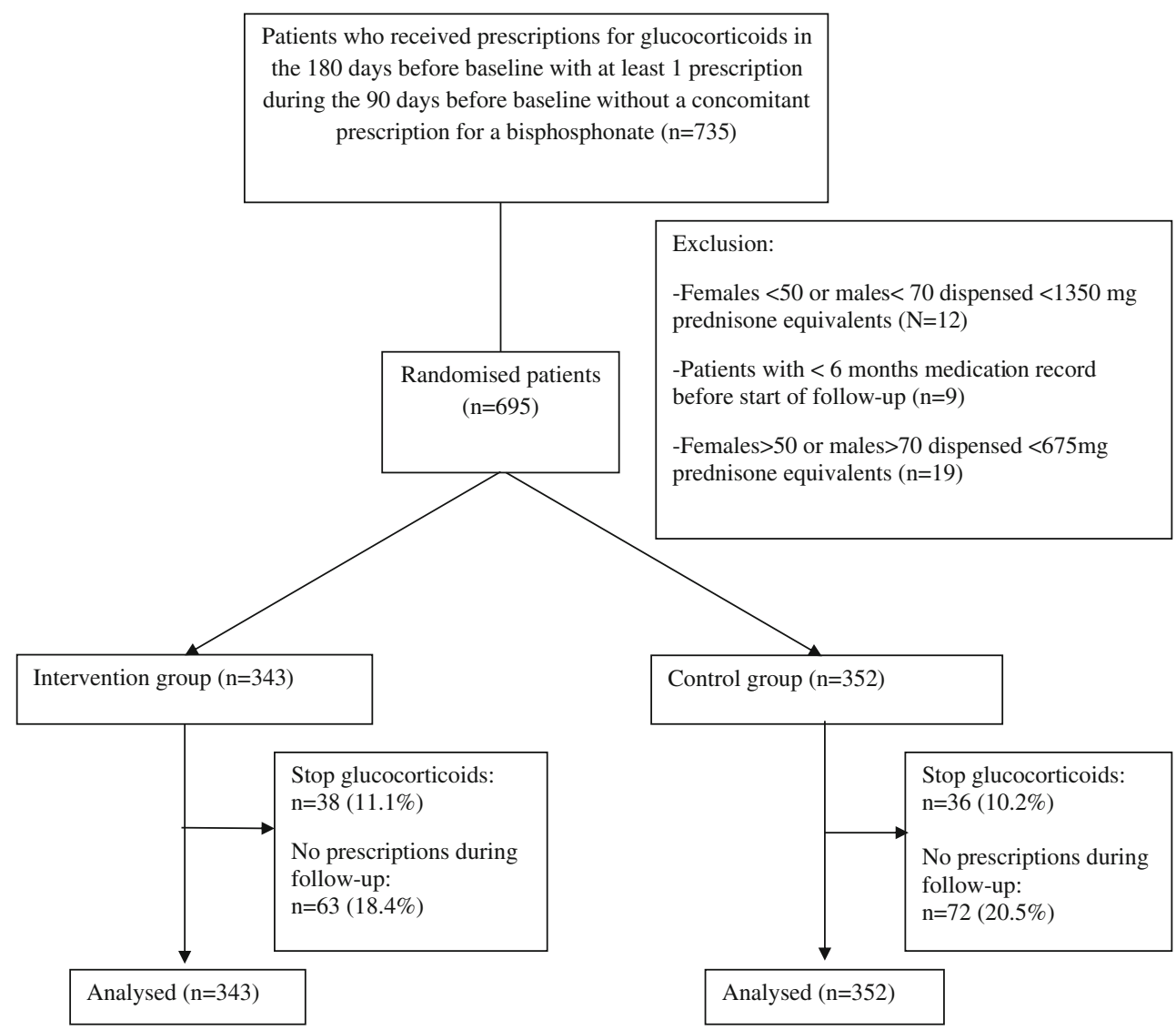


patients $(1.2 \%)$ were excluded as they had medication records available for less than 6 months prior to the first extraction date. Overall, 695 patients could be randomised, with 343 allocated to the intervention group and 352 to the control group. During the follow-up period, $38(11.1 \%)$ patients who were allocated to the intervention group and 36 $(10.2 \%)$ patients in the control group did not receive any new glucocorticoid prescription but did collect prescriptions for other drugs. Furthermore, $63(18.4 \%)$ patients in the intervention group and $72(20.5 \%)$ patients in the control group did not collect any prescription during follow-up (Fig. 1).

The group assigned to the intervention was slightly younger than the control group $(65.9 \pm 16.9$ vs. $68.7 \pm 15.4$ years, $p=$ 0.02 ) and used hydrocortisone more often in the 6 months before baseline ( $7.0 \%$ vs. $3.1 \%, p=0.02)$. All other baseline characteristics and mean follow-up time were similar between the intervention and the control group (Table 1).

During a mean follow-up period of 6.2 months, the primary endpoint (a prescription for a bisphosphonate during follow-up) was achieved by 39 patients $(11.4 \%)$ in the intervention group and by 28 patients $(8.0 \%)$ in the control group. Figure 2 shows the time to initiation of a bisphosphonate for both study groups. The intervention did not significantly increase the prescribing rate of bisphosphonates when compared to the control group (unadjusted HR 1.47, $95 \%$ confidence interval [CI] 0.91-2.39). This effect changed marginally after adjustment for age and use of hydrocortisone in the 6 months before baseline (Table 2). However, subgroup analyses showed that the prescribing rate of bisphosphonates was significantly increased in the intervention group for male patients (12.8\% vs. $5.1 \%$; unadjusted HR $2.53,95 \%$ CI 1.11-5.74; adjusted HR 2.55, $95 \%$ CI 1.12-5.80) and for patients older than 70 years ( $13.4 \%$ vs. $4.9 \%$; unadjusted HR $2.88,95 \%$ CI 1.33-6.23; adjusted HR 2.99, 95 \% CI 1.386.47). The received cumulative number of DDD prednisone equivalents in the 6 months before baseline did not change the effect of the intervention. Similar results were seen for the composite endpoint of any prophylactic osteoporosis drug (Table 3).

\section{Discussion}

This randomised controlled trial showed that active identification of GIOP-eligible patients by community pharmacists did not significantly increase the prescribing rate of bisphosphonates in the total study population. However, subgroup analyses showed that there was a significant increase in the primary endpoint in males and in the elderly ( $>70$ years). Similar results were seen for the composite endpoint of any prophylactic osteoporosis drug (bisphosphonate, calcium, or vitamin D).

To the best of our knowledge, this is the first randomised controlled trial where pharmacists identified GIOP-eligible patients and subsequently contacted the prescriber, without further training of the patient or the physician [22]. The only previously conducted pharmacy-based randomised controlled

Table 1 Baseline characteristics of patients in the intervention group and control group

\begin{tabular}{|c|c|c|c|}
\hline & $\begin{array}{l}\text { Control } \\
\text { group } \\
N=352\end{array}$ & $\begin{array}{l}\text { Intervention } \\
\text { group } \\
N=343\end{array}$ & $p$ value \\
\hline Follow-up (mean \pm SD months) & $6.2 \pm 1.1$ & $6.2 \pm 1.1$ & NS \\
\hline Female & $55.4 \%$ & $54.5 \%$ & NS \\
\hline Age (mean \pm SD years) & $68.7 \pm 15.4$ & $65.9 \pm 16.9$ & 0.02 \\
\hline \multicolumn{4}{|l|}{ Age categories } \\
\hline$<50$ years & $11.6 \%$ & $18.4 \%$ & 0.01 \\
\hline $50-70$ years & $36.1 \%$ & $31.5 \%$ & NS \\
\hline$>70$ years & $52.3 \%$ & $50.1 \%$ & NS \\
\hline
\end{tabular}

Type of glucocorticoid in the 6 months before baseline ${ }^{\mathrm{a}}$

\begin{tabular}{lccl} 
Betamethasone & $1.4 \%$ & $0.3 \%$ & $\mathrm{NS}$ \\
Cortisone acetate & $3.1 \%$ & $4.4 \%$ & $\mathrm{NS}$ \\
Dexamethasone & $7.9 \%$ & $6.1 \%$ & $\mathrm{NS}$ \\
Fludrocortisone & $2.0 \%$ & $2.9 \%$ & $\mathrm{NS}$ \\
Hydrocortisone & $3.1 \%$ & $7.0 \%$ & 0.02 \\
Methylprednisolone & $0.3 \%$ & $0.3 \%$ & $\mathrm{NS}$ \\
Prednisolone & $17.2 \%$ & $17.2 \%$ & $\mathrm{NS}$ \\
Prednisone & $79.3 \%$ & $75.5 \%$ & $\mathrm{NS}$ \\
Triamcinolone & $1.7 \%$ & $1.5 \%$ & $\mathrm{NS}$ \\
Cumulative DDDs of & $183.3 \pm$ & $185.0 \pm$ & $\mathrm{NS}$ \\
prednisone equivalents in & 161.4 & 172.3 & \\
the 6 months prior to & & & \\
baseline (mean \pm SD) & & & \\
Cumulative DDD categories & & $37.9 \%$ & $\mathrm{NS}$ \\
$\quad<135$ DDDs & $41.2 \%$ & $50.7 \%$ & $\mathrm{NS}$ \\
$\quad$ 135-270 DDDs & $44.6 \%$ & $11.4 \%$ & $\mathrm{NS}$ \\
$\quad>270$ DDDs & $14.2 \%$ & & \\
o-medication in the 6 months prior to baseline & & $\mathrm{NS}$ \\
Opioid analgesics & $6.2 \%$ & $7.0 \%$ & $\mathrm{NS}$ \\
Cytostatic drugs & $5.7 \%$ & $3.8 \%$ & $\mathrm{NS}$ \\
Anti-emetic drugs & $4.5 \%$ & $2.9 \%$ & $\mathrm{NS}$ \\
Calcium & $16.7 \%$ & $16.6 \%$ & $\mathrm{NS}$ \\
Vitamin D & $6.0 \%$ & $7.0 \%$ & \\
HRT or SERMs & $0.9 \%$ & $2.0 \%$ & $\mathrm{NS}$ \\
Anti-ulcer drugs & $43.6 \%$ & $44.3 \%$ & $\mathrm{NS}$ \\
Bisphosphonate use $>6$ months & $12.2 \%$ & $10.8 \%$ & $\mathrm{NS}$ \\
prior to baseline & & & \\
& & & \\
\hline
\end{tabular}

Comparison of baseline characteristics between groups was significant at $p<0.05$

$H R T$ hormone replacement therapy, SERM selective estrogen receptor modulator, $S D$ standard deviation, $D D D$ defined daily dosage.

${ }^{a}$ Use of more than one type of glucocorticoids per patient is possible 
Fig. 2 Incident bisphosphonate use in the intervention group (black line) and control group (grey line)

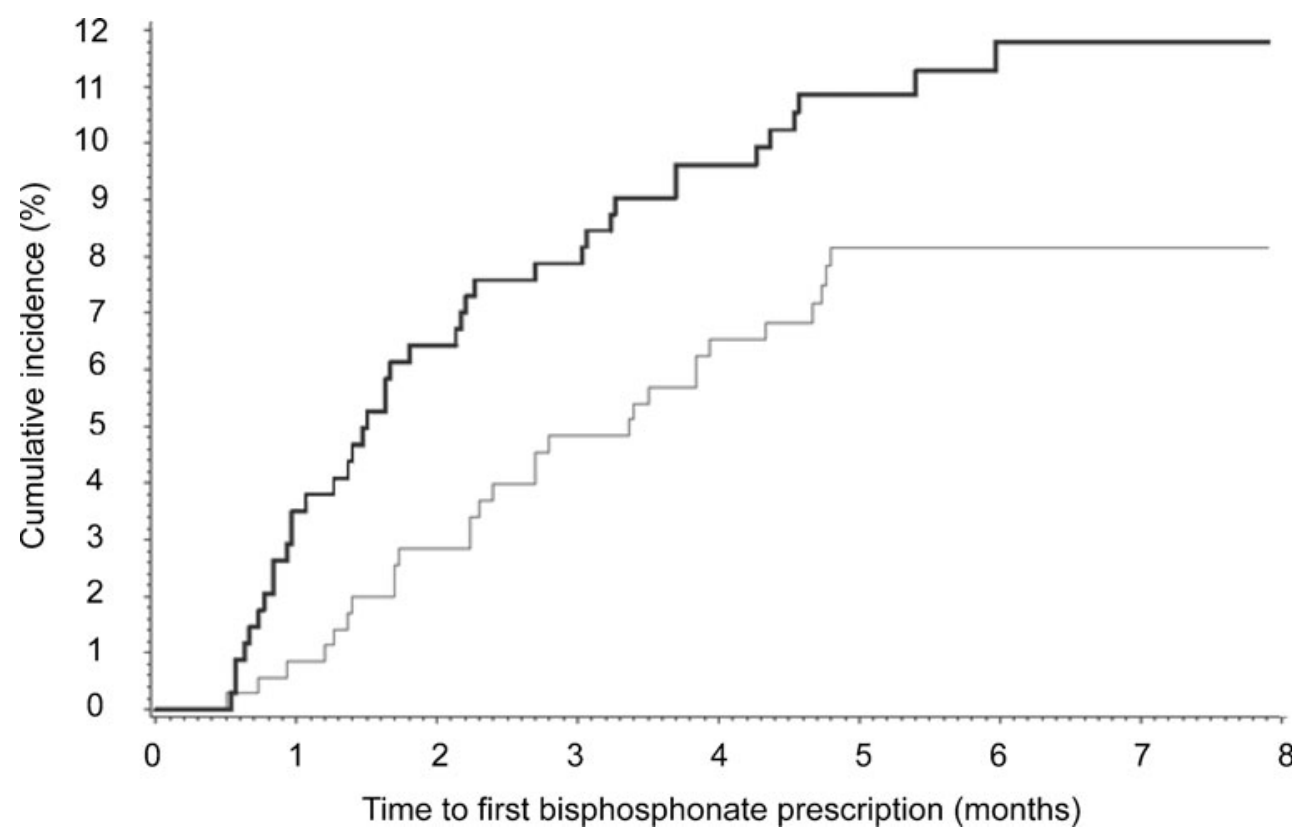

trial that aimed to increase GIOP found an increased prescribing rate of calcium but not of bisphosphonates [19]. This trial was conducted at 15 community pharmacies (intervention 70 patients, control 26 patients). The pharmacists received training for GIOP, identified eligible patients, gave them education for GIOP and contacted the prescriber when necessary. However, pharmacists in both the intervention and control groups received training about GIOP and the importance of bone mineral density (BMD) testing which may have diluted the results. Another randomised controlled trial has shown a twofold increase (28 patients (22\%) intervention group vs. 14 patients (11\%) control group; relative risk $2.1,95 \%$ CI 1.1-3.7) in the composite endpoint of BMD testing or incident osteoporosis treatment with a community pharmacist screening programme [21]. In contrast to the present study, all patients and pharmacists received education about osteoporosis. Other attempts to increase GIOP mostly included educational interventions directed at physicians (general practitioners or rheumatologists) but were often without or with modest results [16-18].
The lack of an overall intervention effect was accompanied by a low number of bisphosphonate-treated patients [14, 17]. It should be noted that the study population did not include patients who already received a prescription for a bisphosphonate in the 6 months prior to baseline. Chitre et al. (2008) similarly excluded these patients and found comparable incident treatment rates for osteoporosis prophylaxis. In addition, our study population included patients who received a bisphosphonate more than 6 months before baseline (10.8\% in the intervention group, $12.2 \%$ in the control group). These patients could have had earlier adverse effects for bisphosphonates or had other reasons for discontinuing these drugs. Moreover, not all patients still used glucocorticoids during follow-up or tapered off the dose, and as a result, GIOP prophylaxis was no longer required.

In the control group, the proportion of GIOP-treated males was twofold lower as compared to females. The neglecting of osteoporosis prophylaxis in males is in line with other studies $[11,14,23]$. The difference in the intervention effect between males and females may be explained by this phenomenon; prescribers may have been more likely to have previously

Table 2 Start of osteoporosis prophylaxis drugs after intervention, as compared to usual care

\begin{tabular}{lllll}
\hline Treatment & Start OP intervention (\%) & Start OP control (\%) & Unadjusted HR (95 \% CI) & Adjusted HR (95 \% CI) \\
\hline Bisphosphonate & 11.4 & 8.0 & $1.47(0.91-2.39)$ & $1.54(0.95-2.50)$ \\
Calcium & 5.3 & 2.6 & $2.06(0.93-4.59)$ & $2.12(0.95-4.72)$ \\
Vitamin D & 3.5 & 1.7 & $2.05(0.77-5.47)$ & $2.08(0.78-5.55)$ \\
Bisphosphonate, calcium or vitamin D & 13.4 & 9.4 & $1.48(0.94-2.31)$ & $1.53(0.98-2.39)$ \\
\hline
\end{tabular}

$O P$ osteoporosis prophylaxis drugs, $H R$ hazard ratio, $C I$ confidence interval

${ }^{\text {a }}$ Adjusted for age categories $(\leq 70,>70)$ and use of hydrocortisone in the 6 months before baseline 
considered osteoporosis prophylaxis in females. The low prescribing rate in the elderly may be explained by the initial belief of physicians that extra treatment with bisphosphonates would be inappropriate due to the presence of multiple comorbidities or a large number of medicines. On the other hand, elderly patients do have a higher absolute fracture risk and the consequences of fractures (especially for those of the hip) can be tremendous [24]. The increased prescribing of bisphosphonates for elderly in the intervention group may be explained by an increased awareness for this fact. It should, however, be noted that the power of this study was not calculated specifically for these subgroup analyses.

Strengths of this study include its size and the simple set-up of the intervention. In contrast to previous trials, patients and physicians were not educated for GIOP and pharmacists only received the recent guideline without further training [19, 21]. This study is therefore a better reflection of the real-life situation. The identification of patients at risk for GIOP can easily be integrated in the tasks of the pharmacists and is not labour intensive or costly when compared to interventions involving education of physicians and/or patients [25]. However, the lack of an overall significant increase in the number of bisphosphonate-treated patients calls for additional measures. The intervention in its present from can be combined with interdisciplinary meetings between pharmacists and general practitioners beforehand and after follow-up, which include feedback about current prescribing and differences between practices. This approach is not very costly and is achievable in daily practice. In addition, clinical rules are currently implemented, and this would make it even easier to extract GIOP-eligible patients from pharmacy information systems. Indeed, a large randomised controlled trial (RCT) showed the significant benefit of a more intensive, pharmacist-led intervention in reducing the number of prescribing errors [26]. Pharmacists did not only give feedback to physicians about medication errors during meetings, but also reviewed medical records and invited the patients.

Table 3 Start of osteoporosis prophylaxis drugs after intervention, as compared to usual care, stratified by gender, cumulative dosage prednisone equivalents and age categories

\begin{tabular}{|c|c|c|c|c|}
\hline & Start OP intervention $(\%)$ & Start OP control $(\%)$ & Unadjusted HR (95\% CI) & Adjusted HR $(95 \% \mathrm{CI})^{\mathrm{a}}$ \\
\hline \multicolumn{5}{|l|}{ Bisphosphonate } \\
\hline Overall & 11.4 & 8.0 & $1.47(0.91-2.39)$ & $1.54(0.95-2.50)$ \\
\hline \multicolumn{5}{|l|}{ Stratified by gender } \\
\hline Men & 12.8 & 5.1 & $2.53(1.11-5.74)$ & $2.55(1.12-5.80)$ \\
\hline Women & 10.2 & 10.3 & $1.03(0.55-1.93)$ & $1.10(0.58-2.06)$ \\
\hline \multicolumn{5}{|c|}{ Stratified by cumulative dosage prednisone equivalents within 6 months before baseline } \\
\hline 67.5-134 DDDs & 10.8 & 7.6 & $1.52(0.69-3.36)$ & $1.54(0.70-3.38)$ \\
\hline 135-270 DDDs & 10.9 & 6.4 & $1.65(0.77-3.56)$ & $1.67(0.77-3.59)$ \\
\hline$>270$ DDDs & 15.4 & 14.0 & $1.48(0.50-4.41)$ & $1.47(0.49-4.38)$ \\
\hline \multicolumn{5}{|c|}{ Stratified by age category ${ }^{\mathrm{b}}$} \\
\hline$\leq 70$ years & 9.4 & 11.3 & $0.84(0.43-1.63)$ & $0.89(0.46-1.73)$ \\
\hline$>70$ years & 13.4 & 4.9 & $2.88(1.33-6.23)$ & $2.99(1.38-6.47)$ \\
\hline \multicolumn{5}{|c|}{ Bisphosphonate, calcium or vitamin D } \\
\hline Overall & 13.4 & 9.4 & $1.48(0.94-2.31)$ & $1.53(0.98-2.39)$ \\
\hline \multicolumn{5}{|l|}{ Stratified by gender } \\
\hline Men & 14.7 & 6.4 & $2.33(1.11-4.89)$ & $2.32(1.10-4.88)$ \\
\hline Women & 12.3 & 11.8 & $1.09(0.61-1.93)$ & $1.14(0.64-2.04)$ \\
\hline \multicolumn{5}{|c|}{ Stratified by cumulative dosage prednisone equivalents within 6 months before baseline } \\
\hline 67.5-134 DDDs & 11.5 & 9.0 & $1.38(0.66-2.89)$ & $1.39(0.66-2.93)$ \\
\hline 135-270 DDDs & 13.8 & 8.3 & $1.61(0.82-3.15)$ & $1.60(0.81-3.15)$ \\
\hline$>270$ DDDs & 17.9 & 14.0 & $1.77(0.62-5.05)$ & $1.74(0.61-4.99)$ \\
\hline \multicolumn{5}{|c|}{ Stratified by age category ${ }^{\mathrm{b}}$} \\
\hline$\leq 70$ years & 13.5 & 12.5 & $1.10(0.61-1.98)$ & $1.16(0.64-2.09)$ \\
\hline$>70$ years & 13.4 & 6.5 & $2.14(1.07-4.30)$ & $2.22(1.11-4.47)$ \\
\hline
\end{tabular}

$O P$ osteoporosis prophylaxis drugs, $H R$ hazard ratio, $C I$ confidence interval, $D D D s$ defined daily dosage prednisone equivalents

${ }^{a}$ Adjusted for age categories $(\leq 70,>70)$ and use of hydrocortisone in the 6 months before baseline

${ }^{\mathrm{b}}$ Adjusted for hydrocortisone use in the 6 months before baseline 
The major limitation of this study is that we do not know how motivated the pharmacists were to perform the intervention. It is likely that pharmacists did not notify all GPs, but this has not been systematically registered. In addition, we do not know if discussions between prescribers and their patients about the start of GIOP took place. Possibly, a number of approached patients refused to start osteoporosis prophylaxis. Therefore, the actual effect of the pharmacist intervention on the physician's behaviour may have been greater than the reported effect. In addition, we had no clinical data available such as (prior) BMD testing or the occurrence of fractures (history). Guidelines recommend that premenopausal women who use $7.5-15 \mathrm{mg}$ of prednisone equivalents for $\geq 3$ months should receive a BMD measurement. However, this study presumably included post-menopausal women ( $\geq 50$ years). Furthermore, we also have included patients who were dispensed less than 135 DDD prednisone equivalents in the 6 months before baseline (41.2 \% in the control group, $37.9 \%$ in the intervention group), who were possibly not eligible for GIOP according to the Dutch guideline. However, in the Netherlands, patients are frequently dispensed medication for 3 months, and we would have missed these patients if the inclusion period was only 3 months before baseline. Moreover, all patients were required to receive a dispensing for glucocorticoids within 3 months before baseline, and our results show that the cumulative number of DDD prednisone equivalents did not modify the intervention effect. Another limitation of this study was that we were unable to exclude patients where osteoporosis prophylaxis would have been contraindicated or inappropriate (e.g. patients with serious cognitive or renal impairment). Finally, this was a non-blinded RCT with a lack of clinical equipoise between the pharmacists in the intervention group [27]. In other words, it is very likely that all included pharmacists saw the importance of the intervention. As a result, pharmacists could have been motivated to selfidentify patients other than those in the intervention group who would also benefit from GIOP. This may have masked the effect of the intervention.

The present study showed that simple feedback by community pharmacists to physicians about patients eligible for GIOP did not manage to significantly increase the prescribing of bisphosphonates in the overall study population. Subgroup analyses showed a significant increase in males and in patients older than 70 years. However, the absolute number of GIOP-treated patients remained low which calls for more intensive pharmacy-based interventions.

Acknowledgments This study was supported by The Netherlands Organization for Health Research and Development (ZonMw; grant number 113101007). The funders had no role in study design, data collection and analysis, decision to publish, or preparation of the manuscript.
Conflicts of interest The Division of Pharmacoepidemiology \& Clinical Pharmacology (employing CK, FV, MK, TvS, TE and MB) has received unrestricted funding from the Netherlands Organisation for Health Research and Development (ZonMW), the Dutch Health Care Insurance Board (CVZ), the Royal Dutch Pharmacists Association (KNMP), the private-public funded Top Institute Pharma (www. tipharma.nl; including co-funding from universities, government, and industry), the EU Innovative Medicines Initiative (IMI), the EU 7th Framework Program (FP7) and the Dutch Ministry of Health and industry (including GlaxoSmithKline, Pfizer and others). The authors TV and JB have no competing interests.

Open Access This article is distributed under the terms of the Creative Commons Attribution Noncommercial License which permits any noncommercial use, distribution, and reproduction in any medium, provided the original author(s) and the source are credited.

\section{References}

1. Mazziotti G, Canalis E, Giustina A (2010) Drug-induced osteoporosis: mechanisms and clinical implications. Am J Med 123:877-884

2. de Vries F, Bracke M, Leufkens HG, Lammers JW, Cooper C, van Staa TP (2007) Fracture risk with intermittent high-dose oral glucocorticoid therapy. Arthritis Rheum 56:208-214

3. van Staa TP, Leufkens HG, Cooper C (2002) The epidemiology of corticosteroid-induced osteoporosis: a meta-analysis. Osteoporos Int 13:777-787

4. van Staa TP, Leufkens HG, Abenhaim L, Zhang B, Cooper C (2000) Oral corticosteroids and fracture risk: relationship to daily and cumulative doses. Rheumatology 39:1383-1389

5. Reid DM, Devogelaer JP, Saag K, Roux C, Lau CS, Reginster JY, Papanastasiou $\mathrm{P}$ et al (2009) Zoledronic acid and risedronate in the prevention and treatment of glucocorticoid-induced osteoporosis (HORIZON): a multicentre, double-blind, double-dummy, randomised controlled trial. Lancet 11:1253-1263

6. Reid DM, Hughes RA, Laan RF, Sacco-Gibson NA, Wenderoth DH, Adami S, Eusebio RA et al (2000) Efficacy and safety of daily risedronate in the treatment of corticosteroid-induced osteoporosis in men and women: a randomized trial. European Corticosteroid-Induced Osteoporosis Treatment Study. J Bone Miner Res 15:1006-1013

7. $\mathrm{CBO}$ guideline, Osteoporose en fractuurpreventie, derde herziening 2011, url: www.cbo.nl, assessed at 28 Jan 2013

8. Geusens PP, de Nijs RNJ, Lems WF, Laan RFJM, Struijs A, van Staa TP, Bijlsma JWJ (2004) Prevention of glucocorticoid osteoporosis: a consensus document of the Dutch Society for Rheumatology. Ann Rheum Dis 63:324-325

9. Grossman JM, Gordon R, Ranganath VK, Deal C, Caplan L, Chen W, Curtis JR, Furst DE, McMahon M, Patkar NM, Volkmann E, Saag KG (2010) American College of Rheumatology 2010 recommendations for the prevention and treatment of glucocorticoid-induced osteoporosis. Arthritis Care Res (Hoboken) 62:1515-1526

10. Stafford RS, Drieling RL, Hersh AL (2004) National trends in osteoporosis visits and osteoporosis treatment, 1988-2003. Arch Intern Med 164:1525-1530

11. Feldstein AC, Elmer PJ, Nichols GA, Herson M (2005) Practice patterns in patients at risk for glucocorticoid-induced osteoporosis. Osteoporos Int 16:2168-2174

12. Ryan JG, Morgan RK, Lavin PJ, Murray FE, O'Connell PG (2004) Current management of corticosteroid-induced osteoporosis: variations in awareness and management. Ir J Med Sci 173:20-22

13. Yood RA, Harrold LR, Fish L, Cernieux J, Emani S, Conboy E, Gurwitz JH (2001) Prevention of glucocorticoid-induced osteoporosis. Arch Intern Med 161:1322-1327 
14. Duyvendak M, Naunton M, Atthobari J, van den Berg PB, Brouwers JR (2007) Corticosteroid-induced osteoporosis prevention: longitudinal practice patterns in The Netherlands 2001-2005. Osteoporos Int 18:1429-1433

15. Naunton M, Peterson GM, Jones G, Griffin GM, Bleasel MD (2004) Multifaceted educational program increases prescribing of preventive medication for corticosteroid induced osteoporosis. J Rheumat 31: $550-556$

16. Curtis JR, Westfall AO, Allison J, Becker A, Melton ME, Freeman A, Kiefe CI et al (2007) Challenges in improving the quality of osteoporosis care for long-term glucocorticoid users. A prospective randomized trial. Arch Intern Med 167:591-596

17. Solomon DH, Katz JN, la Tourette AM, Coblyn JS (2004) Multifaceted intervention to improve rheumatologists' management of glucocorticoid-induced osteoporosis: a randomized controlled trial. Arthr Rheum 51:383-387

18. Chitre MM, Hayes W (2008) 3-Year results of a member and physician intervention to reduce risk associated with glucocorticoidinduced osteoporosis in a health plan. J Manag Care Pharm $14: 281-290$

19. McDonough RP, Doucette WR, Kumbera P, Klepser DG (2005) An evaluation of managing and educating patients on the risk of glucocorticoid-induced osteoporosis. Value Health 8:24-31

20. Buurma H, Bouvy ML, De Smet PA, Floor-Schreudering A, Leufkens HG, Egberts AC (2008) Prevalence and determinants of pharmacy shopping behaviour. J Clin Pharm Ther 33:17-23
21. Yuksel N, Majumdar SR, Biggs C, Tsuyuki RT (2010) Community pharmacist-initiated screening program for osteoporosis: randomized controlled trial. Osteoporos Int 21:391-398

22. Elias MN, Burden AM, Cadarette SM (2011) The impact of pharmacist interventions on osteoporosis management: a systematic review. Osteoporos Int 22:2587-2596

23. Majumdar SR, Lix LM, Yogendran M, Morin SN, Metge CJ, Leslie WD (2012) Population-based trends in osteoporosis management after new initiations of long-term systemic glucocorticoids (19982008). J Clin Endocrinol Metab 97:1236-1242

24. Kanis JA, Johansson H, Oden A, Johnell O, De Laet C, Melton IL, Tenenhouse A, Reeve J, Silman AJ, Pols HA, Eisman JA, McCloskey EV, Mellstrom D (2004) A meta-analysis of prior corticosteroid use and fracture risk. J Bone Miner Res 19:893-899

25. Laliberté MC, Perreault S, Jouini G, Shea BJ, Lalonde L (2011) Effectiveness of interventions to improve the detection and treatment of osteoporosis in primary care settings: a systematic review and meta-analysis. Osteoporos Int 22:2743-2768

26. Avery AJ, Rodgers S, Cantrill JA, Armstrong S, Cresswell K, Eden M, Elliott RA, Howard R, Kendrick D, Morris CJ, Prescott RJ, Swanwick G, Franklin M, Putman K, Boyd M, Sheikh A (2012) A pharmacist-led information technology intervention for medication errors (PINCER): a multicenter, cluster randomized, controlled trial and cost-effectiveness analysis. Lancet 379:1310-1319

27. Freedman B (1987) Equipoise and the ethics of clinical research. $N$ Eng J Med 317:141-145 